\title{
edmetic
}

Revista de Educación Mediática y TIC

Las TIC en los entornos educativos

Fecha de recepción: dd/mm/año

Fecha de revisión: $\mathrm{dd} / \mathrm{mm} / a n ̃ o$

Fecha de aceptación: dd/mm/año 


\section{Las TIC en los entornos educativos}

La transición desde un modelo educativo centrado en la enseñanza hacia un modelo centrado en el aprendizaje, supone un gran cambio metodológico y por ende cultural que ha de ser considerado en todas las instituciones educativas.

Se precisa pues, de un plan estratégico donde se encuentren inmersas propuestas al respecto de la innovación metodológica, la aparición de pedagogías emergentes, la visualización y ejemplificación manifiesta de buenas prácticas educativas, la formación del profesorado, el valor de lo social, la consideración del aprendizaje-servicio, la incardinación de las emociones en los procesos de enseñanza-aprendizaje y en última instancia la definición precisa de un modelo educativo con carácter propio que haga referencia expresa a las comunidades de aprendizaje.

El valor del aprendizaje dialógico ha de quedar expreso en prácticas de integración TIC en todos los niveles del sistema educativo para promover de manera acelerada la participación, el ejercicio del liderazgo transformacional, la inteligencia colectiva, la competencia emocional, el aula invertida, etc., como apuesta para la innovación del currículum en su conjunto.

Del mismo modo, el aprendizaje a lo largo de la vida se conforma cambiante y acelerado, en la necesidad de un entendimiento dinámico capaz de potenciar la resiliencia adaptativa a nuevas situaciones que en lo social se suceden incesantemente. Manipulación del conocimiento eficaz, selección de contenido, entendimiento de lo aprendido, predisposición hacia el otro, comprensión del colectivo como factor de enriquecimiento continuado, se conforman necesarios en un mundo de permanente $y$ vertiginoso cambio al que la institución educativa no puede permanecer al margen.

La obsolescencia del conocimiento es cada vez más acelerada y, en este sentido, quizás las TIC y su integración en los procesos de enseñanza- 
aprendizaje sean una oportunidad para un cambio de modelo que argumente prioritario el valor de la inteligencia colectiva, la eficacia y ayuda de la tecnología en base a su correcta integración desde nuevas concepciones metodológicas que integren nuevas y viejas formas de proceder, donde la evaluación sea eminentemente competencial, aparezcan nuevas formas de organización y exigencia de nuevas definiciones al respecto de las actividades y donde el aprender a aprender tenga valor propio.

La participación activa del alumnado se convierte en requisito, dependiendo y conformándose desde su compromiso, actividad e implicación y generándose espacios más formativos basados en aprendizajes más significativos y facilitando la transferencia y aplicabilidad en contextos diferenciados.

La integración de las TIC, emerge en todas y cada una de las propuestas de intervención innovadoras desarrolladas, como oportunidad para la conformación del valor del grupo al respecto de la individualidad. Prácticas y dinámicas de inteligencia colectiva que corroboran la eficacia de la multitud en base organizada y planificada y donde la energía del acto comunicativo se revierte eficaz en cada nexo de unión. Las emociones, que transgreden las redes, quedan manifiestas en cada enlace, en cada vínculo, que sin haber pretendido de inicio se conforma emotivo. Quizás este sea el poder de la tecnología y su integración en la educación. Sin haberlo pretendido, al enlazar a personas, enlaza sus ideas, sus actos creativos y por ende su amor.

Así, cargadas de emociones se configuran las experiencias que presentamos a continuación y que, sin duda, advierten de la necesidad de cambio e innovación en la institución educativa y la certeza del valor de la integración TIC como, principalmente, enlace de personas. Sólo, con una actitud abierta al cambio, hay que dejarse llevar por la corriente. Muchas son las ideas que fluyen en torno a ambos lados de la orilla.

El monográfico inicia su recorrido con la aportación de Sarah Arseguel y 
María Luisa Renau que presentan un enfoque abierto del desarrollo de la competencia digital y cultural basada en la conformación de comunidades de aprendizaje en torno a interacciones sociales que conjugan como referente los blogs educativos. Una apuesta decidida por la integración TIC tomando como valor y foco la participación colaborativa de lo social, conformándose a su alrededor aspectos motivacionales de gran valor y apostando decididamente por las metodologías activas y las pedagogías emergentes. En definitiva, constructivismo social, comunidades de práctica, concepción de la educación como superación de una mera transmisión de conocimientos, etc., son valores de reseña en todo el artículo.

Por su parte, Clenticia Ballestero y Judith Batista reflejan como la enseñanza del inglés, como lengua extranjera, se ha convertido en factor predominante dentro de los planes de estudio de la mayoría de las carreras impartidas a nivel universitario, considerándose focal para una enseñanza con un carácter más significativo, fiable y válido. La visión ofrecida, al respecto de las percepciones de los estudiantes acerca de su integración curricular y la necesidad de la interacción y transversalidad es absolutamente magistral y detalla su relevancia.

La necesidad de futuras investigaciones que subrayen la importancia de las metodologías activas, la integración de redes y herramientas web sociales en los procesos de enseñanza-aprendizaje, el desarrollo de la competencia emocional, propuestas de trabajo basadas en el desarrollo cierto de las competencias básicas, comunidades virtuales y conectivismo, que potencien nuevas formas de aprender y participar, renovación e innovación donde el usuario sea el verdadero protagonista de su práctica, construcción educativa, búsqueda de la gestión y la practicidad del conocimiento, quedan reflejas en la aportación de Juan Manuel Trujillo et al. Los aprendizajes basados en problemas (PBL) se conforman como una oportunidad para la comunicación, la colaboración participativa, el compromiso, el ejercicio de un sentir transformacional, la innovación reflexivo-crítica, entre otras. Una oportunidad 
para la expresión compartida que irradie en forma significativa un pensamiento vivido fruto de la interacción efectiva con el medio desde el ejercicio de la competencia emocional.

La aportación de Ricardo Chrobak et al, como no podía ser de otro modo, manifiesta la relevancia del uso e integración de los mapas conceptuales para su integración en los procesos de enseñanza-aprendizaje incidiendo en su potencial para el aprendizaje y especialmente para el desarrollo de la creatividad. Existe una relación entre el proceso de construcción de mapas conceptuales y el proceso creativo y así queda reflejo en el trabajo. Del mismo modo, se resalta la importancia del aprendizaje significativo y se profundiza en los diferentes principios que guían la creación de mapas conceptuales. Cmaptools aparece refleja como una herramienta a ser considerada en el ámbito educativo ya que su utilización planificada puede tener resultados significativos en la mejora de los aprendizajes.

Laura Corazza, refleja desde el laboratorio MELA de la Universidad de Bolonia, la experimentación al respecto de la integración y uso del vídeo en los procesos de enseñanza-aprendizaje, fundamentado en la relevancia e influjo de los medios de comunicación, internet, dispositivos móviles, etc., sobre la adolescencia. El análisis muestra como la integración del vídeo a través de herramientas digitales estimula la atención y el interés, siendo capaz de adaptarse a los diferentes estilos de aprendizaje y tiempos, estimulando del mismo modo la participación y la inclusión. El uso del vídeo en la enseñanza tiene un impacto positivo, concluye, en actividades desarrolladas con alumnado con dificultades de aprendizaje especialmente.

$M^{a}$ Amor Martín et al, apuestan por un modelo social participativo y de desarrollo tecnológico, a través de las redes sociales de Internet y las vías de comunicación que giran en torno a ellas conformándose el valor de la inteligencia colectiva. Una nueva dimensión de la comunicación que va más allá del lenguaje individual. El flash mob, como método de enseñanzaaprendizaje, por sus características, posibilita el desarrollo de competencias 
comunicativas y sociales (lingüística, mediática, informacional, audiovisual, digital, social y ciudadana), reseñan. Se exponen, del mismo modo, dinámicas llevadas a cabo para su implementación en torno a la planificación y diseño de metodologías activas, potenciando la implicación de la ciudadanía y su repercusión mediática.

La última aportación de este monográfico, corre a cargo de Ángel Ramón Mirabal et al, exponiendo una clasificación identificativa de las competencias tecnológicas de los docentes al respecto del uso de Moodle como complemento a sus clases presenciales. Se elige para ello un enfoque cualitativo que considera, por un lado, la revisión de estándares de competencias establecidos por estudios anteriores e instituciones vinculadas a la formación docente, y por otro, el análisis inductivo a partir de la observación directa del trabajo en Moodle. Los resultados confirman la necesidad de la formación del profesorado al respecto de la competencia digital como punto de inflexión para la mejora de la calidad educativa.

Juan Manuel Trujillo Torres Universidad de Granada 